\title{
Lacticin 481 Synthetase Phosphorylates Its Substrates During Lantibiotic Production
}

Champak Chatterjee, Leah M. Miller, Yong L. Leung, Lili Xie, Myongsin Yi, Neil L. Kelleher, and Wilfred A van der Donk

Department of Chemistry, University of Illinois at Urbana-Champaign, 600 South Mathews Avenue, Urbana, Illinois 61801

\section{General Methods}

Fmoc-L-Ala loaded Wang resin $(0.612 \mathrm{mmol} / \mathrm{g}$ substitution) was purchased from Chem-Impex (Wood Dale, IL). Standard Fmoc-L-amino acids (AAs) were purchased from Advanced ChemTech (Louisville, KY) or Chem-Impex. The phosphoamino acids Fmoc-L-Ser(PO(OBzl)OH)-OH and FmocL-Thr(PO(OBzl)OH)-OH were purchased from Novabiochem (San Diego, CA). The coupling additive HOBt (1-hydroxybenzotriazole) and coupling reagent HBTU ( $O-\left(1 \mathrm{H}-\right.$ benzotriazole-1-yl)- $N, N, N^{\prime}, N^{\prime}-$ tetramethyluroniumhexafluorophosphate) were purchased from Advanced ChemTech. The coupling reagent $\mathrm{TBTU}^{1} \quad\left(O\right.$-(1H-benzotriazole-1-yl)- $N, N, N^{\prime}, N^{\prime}$-tetramethyluroniumtetrafluoroborate $)$ was purchased from Novabiochem. $N, N^{\prime}$-Diisopropylcarbodiimide (DIC) was purchased from Aldrich Chemical Co (Milwaukee, WI). Common solvents for peptide synthesis and purification, dimethylformamide (DMF), trifluoroacetic acid (TFA), dichloromethane (DCM), and acetonitrile $(\mathrm{MeCN})$, were purchased in HPLC grade or better, and used as provided. Piperidine and pyridine were purchased from Acros. Thioanisole, anisole, phenol, triisopropyl silane (TIS) and ethanedithiol (EDT) were purchased from Aldrich Chemical Co. Diisopropylethylamine (DIEA) used for the coupling of phosphoamino acids was distilled prior to use. Automated solid phase peptide synthesis was undertaken on a Rainin PS3 synthesizer. Analytical reversed-phase HPLC was performed on a either a Beckman Gold system (Gold 125 module with a model 166 UV detector) or a Rainin Dynamax system (Dynamax model SD-200 pump and UV-1 detector). Preparative HPLC was performed on a Waters system (Model 600 controller and pump, 2487 dual wavelength absorbance detector). Vydac analytical C4 and C18 columns (5 micron, $0.46 \mathrm{~cm} \times 25 \mathrm{~cm}$ ), and Waters C4 and C18 PrepLCTM (25 mm module) columns were used for peptide purification. The flow-rates for analytical and preparative HPLC were $1 \mathrm{~mL} / \mathrm{min}$ and $8 \mathrm{~mL} / \mathrm{min}$ respectively and detection was at $220 \mathrm{~nm}$. All runs employed a linear gradient of 2-100\% solvent B. Solvent A was $0.1 \%$ aqueous TFA and solvent B was $80 \%$ aqueous acetonitrile containing $0.086 \%$ TFA. The thiol-cyanylating reagent 1-cyano-4-dimethylaminopyridinium tetrafluoroborate (CDAP) was purchased from Sigma (St. Louis, MO). Routine matrix assisted laser desorption ionization time-of-flight (MALDI-TOF) MS analysis was conducted for all peptides and assay products on an Applied Biosystems Voyager-DE STR instrument in linear mode at an accelerating voltage of 20,000 V. The instrument has an accuracy of $0.05 \%$ for small to medium sized peptides and proteins when external calibration is used. Assay products were analyzed in one of two ways. In the first method, $1 \mu \mathrm{L}$ of the assay mixture was mixed with $9 \mu \mathrm{L}$ of 3,5-dimethoxy-4-hydroxycinnamic (sinapic) acid (prepared in 30\% acetonitrile, containing 0.1\% TFA) matrix (Fluka, Switzerland), and $1 \mu \mathrm{L}$ of the mixture was spotted on the MALDI target. A second procedure involved centrifugation of the assay mixtures at $14 \mathrm{~kg}$ in a microfuge, removal and acidification of the supernatant with 5\% TFA. The acidified supernatant was then purified by C18 Zip-Tip (Millipore, Billerica, MA), and the assay product eluted directly with $4 \mu \mathrm{L}$ of $\alpha$-cyano-4-hydroxycinnamic acid (prepared in $50 \%$ acetonitrile, containing $0.1 \%$ TFA) of which $1 \mu \mathrm{L}$ was spotted on the MALDI target. Electrospray ionization Fourier-transform mass spectrometry (ESI-FTMS) analyses of assay intermediates were performed on a custom-built 8.5 T Quadrupole-FTMS Hybrid instrument. Peptide masses were computed by the PAWS Software (Beavis, R. C., and Fenyö, D., ProteoMetrics, LLC, New York). Target peptides were cloned in pET15b (Novagen, Madison, WI) as fusions with the GyrA intein and chitin binding domain (CBD) 
obtained from the pTXB1 vector (New England Biolabs, Beverly, MA). Purification by chitin affinity followed by intein-mediated cleavage generated the desired peptide thioesters. Fusion proteins were analyzed by sodium dodecyl sulfate polyacrylamide gel electrophoresis (SDS-PAGE) using the protocols of Maniatis et al. ${ }^{2} \mathrm{UV}$-vis spectroscopic data were recorded on a Hewlett-Packard model 8453 UV-vis spectrophotometer or a Cary 100 Bio UV-vis spectrophotometer (Varian, Palo Alto, CA).

\section{Peptide Synthesis}

All peptides were synthesized on a $0.1 \mathrm{mmol}$ scale employing Fmoc-based solid-phase peptide synthesis protocols. The C-terminal amino acid was chosen to be alanine for all synthetic peptides for the ease of synthesis. Coupling and deprotection steps were undertaken at room temperature in DMF as the solvent and agitation by bubbling nitrogen through the suspension. Deprotection of the Fmoc- group was achieved with $20 \%$ Piperidine in DMF for 4 x 5 min. Coupling of amino acids was undertaken for at least $1 \mathrm{~h}$ with $0.4-0.8 \mathrm{mmol}$ (4-8 equivalents) of each Fmoc-L-AA, and HBTU, per coupling in the presence of $0.4 \mathrm{M} \mathrm{N}$-methylmorpholine (NMM) in DMF. Couplings were monitored by the Kaiser test and coupling times adjusted as required. ${ }^{3}$ To minimize racemization Fmoc-L-Cys(Trt)-OH was manually coupled in a base-free manner employing equimolar amounts of DIC and $\mathrm{HOBt}^{4}{ }^{4} \mathrm{Fmoc}-\mathrm{L}-$ $\mathrm{Ser}(\mathrm{PO}(\mathrm{OBzl}) \mathrm{OH})-\mathrm{OH}$ and Fmoc-L-Thr(PO(OBzl)OH)-OH were also coupled manually using equimolar amounts of HOBt, and TBTU, or HBTU, and two equivalents of DIEA per equivalent of phosphoamino acid. After synthesis, the resin was washed successively with DMF, ethanol, and DCM and dried in vacuo prior to cleavage of the peptide from the resin. Peptide cleavage from the resin and global deprotection was achieved with a mixture of TFA, water, and EDT $(95: 2.5: 2.5)$ with the dropwise addition of triisopropylsilane until a colorless suspension, indicating consumption of the trityl cation, was obtained. For peptides containing phosphoamino acids, $2 \%$ anisole $(\mathrm{v} / \mathrm{v})$ was added to the cleavage mixture to trap the benzyl cation. Crude peptides were precipitated and washed with cold diethyl ether, and lyophilized from $\sim 10 \%$ aqueous acetic acid after filtration through a $0.45 \mu \mathrm{m}$ filter. Lyophilized crude peptides were purified by C18 preparative RP-HPLC and the pure products were characterized by MALDI-TOF MS or ESI-MS.

Synthesis of CNMNSA. ESI MS calcd. 638.7 Da. Observed, 639.5 Da. Synthesis of CGVIHpTISHEA. MALDI-TOF MS calcd. 1246.3 Da. Observed, 1246.9 Da. Synthesis of CGVIHpTIAHECA. ESI-MS calcd. 1333.4 Da. Observed, 1334.6 Da. Synthesis of CGVIHpTIpSHECNMNpSWA. MALDI-TOF MS calcd. 2142.1 Da. Observed, 2140.1 Da

\section{Isolation of Peptide Thioesters}

BL21(DE3) cells transformed with the pET15b plasmid encoding either the His 6 -LctA(1-37)-inteinCBD fusion protein or $\mathrm{His}_{6}$-LctA(1-27)-intein-CBD fusion protein, were grown in $3 \mathrm{~L} \mathrm{LB}(100 \mu \mathrm{g} / \mathrm{mL}$ ampicillin) until $\mathrm{OD}_{600}$ 0.6-0.7. Protein expression was induced with $0.65 \mathrm{mM} \mathrm{IPTG}$, and the cells were grown for an additional $6 \mathrm{~h}$ at $25^{\circ} \mathrm{C}$. At the end of induction the cells were harvested by centrifugation at $18.5 \mathrm{~kg}$ for $15 \mathrm{~min}$ at $4{ }^{\circ} \mathrm{C}$, and the cell pellet $(\sim 9 \mathrm{~g})$ was resuspended in $20 \mathrm{~mL}$ of cell lysis buffer $(20$ $\mathrm{mM}$ Tris-HCl, $\mathrm{pH}$ 8.0, $1 \mathrm{M} \mathrm{NaCl}, 1 \mathrm{mM}$ EDTA, 0.1\% Triton-X-100) and lysed by sonication at an amplitude of $75,3 \mathrm{~s}$ on, $10 \mathrm{~s}$ off for $15-20 \mathrm{~min}$ on ice. The lysate was centrifuged at $27 \mathrm{~kg}$ for $30 \mathrm{~min}$, and the supernatant containing the fusion protein was bound to a pre-equilibrated chitin column $(30 \mathrm{~mL})$ at $4{ }^{\circ} \mathrm{C}$ for $2 \mathrm{~h}$ with gentle shaking. The column was subsequently washed with at least twenty column volumes of column buffer A containing $20 \mathrm{mM}$ HEPES, pH 7.2, $500 \mathrm{mM} \mathrm{NaCl}$, and $1 \mathrm{mM}$ EDTA until 
$\mathrm{OD}_{280}$ of the flow through was less than 0.01 . At this point the column was washed with three column volumes of column buffer B (100 mM HEPES, pH 7.75, $200 \mathrm{mM} \mathrm{NaCl}, 1 \mathrm{mM}$ EDTA). For overnight intein-mediated cleavage of the truncated His $_{6}$-LctA mutants, and generation of the MESNa thioester, the column was equilibrated with $50 \mathrm{~mL}$ of column buffer B containing $50 \mathrm{mM}$ MESNa for 12-14 $\mathrm{h}$ at 4 ${ }^{\circ} \mathrm{C}$. The eluate containing the peptide thioester was concentrated by Amicon YM1 membrane (Millipore, Billerica, MA) and lyophilized after acidification with $0.1 \%$ TFA. The lyophilized peptide thioester was purified by Waters preparative C4 RP-HPLC and analyzed by MALDI-TOF MS.

Isolation of $\mathrm{His}_{6}$-LctA(1-37)-MESNa. MALDI-TOF MS calcd. $6181.8 \mathrm{Da}(-\mathrm{Na}+\mathrm{H})$. Observed 6182.9 Da.

Isolation of $\mathrm{His}_{6}-\mathrm{LctA}(1-27)-\mathrm{MESNa}$. MALDI-TOF MS calcd. $5120.6 \mathrm{Da}(-\mathrm{Na}+\mathrm{H})$. Observed 5122.8 $\mathrm{Da}$

\section{Generation of truncated LetA analogs}

The purified lyophilized synthetic peptides were redissolved in a minimum volume of ligation buffer (typically 50-250 $\mu \mathrm{L}$ ) containing $100 \mathrm{mM}$ HEPES, $\mathrm{pH} 7.75,200 \mathrm{mM} \mathrm{NaCl}$, and $50 \mathrm{mM} \mathrm{MESNa}$, to a final concentration of $4.6 \mathrm{mM}$ (CGVIHpTIpSHECNMNpSNWA), $17 \mathrm{mM}$ (CGVIHpTIAHECA), 41 $\mathrm{mM}$ (CGVIHpTISHEA), or $109 \mathrm{mM}$ (CNMNSA). The peptide solution was directly added to the lyophilized peptide thioester to obtain a final concentration of $\sim 1 \mathrm{mM}$ of the thioester. The $\mathrm{pH}$ was adjusted to 7.6-7.8, and ligation allowed for $12-16 \mathrm{~h}$ at $4{ }^{\circ} \mathrm{C}$. The crude ligation products were analyzed by MALDI-TOF MS for completeness of the reaction prior to acidification with 5\% TFA. Thus, $1 \mu \mathrm{L}$ of the ligation mixture was mixed with $9 \mu \mathrm{L}$ of sinapic acid matrix (Fluka, Switzerland) and $1 \mu \mathrm{L}$ of the mixture was spotted on the MALDI target. The acidified ligation mixture was incubated with $60 \mathrm{mM}$ TCEP for $30 \mathrm{~min}$ at $25{ }^{\circ} \mathrm{C}$ prior to purification by $\mathrm{C} 4$ analytical RP-HPLC. Fractions containing the ligation products were identified by MALDI-TOF MS.

Ligation of His $_{6}$-LctA(1-37)-MESNa thioester with CNMNSA. MALDI-TOF MS calcd. 6678.3 Da. Observed, 6677.4 Da.

Ligation of His $_{6}$-LctA(1-27)-MESNa thioester with CGVIHpTISHEA. MALDI-TOF MS calcd. 6224.7 Da. Observed, 6225.7 Da.

Ligation of His 6 -LctA(1-27)-MESNa thioester with CGVIHpTIAHECA. MALDI-TOF MS calcd. 6311.9 Da. Observed, 6312.5 Da.

Ligation of His ${ }_{6}$-LetA(1-27)-MESNa thioester with CGVIHpTIpSHECNMNpSWA. MALDI-TOF MS calcd. 7120.5 Da. Observed, 7119.4 Da.

\section{Assays with LetM and ATP}

Lyophilized C4 HPLC fractions containing the ligation products were redissolved in sterile Millipore water to obtain final concentrations of 1-4 $\mathrm{mM}$ in peptide. The peptide solution was incubated at room temperature with 1-3 $\mu \mathrm{M} \mathrm{LctM}$ in a buffer containing $50 \mathrm{mM}$ Tris- $\mathrm{HCl}, \mathrm{pH} 7.5,10 \mathrm{mM} \mathrm{MgCl}_{2}$, $5 \mathrm{mM}$ ATP, $5 \mu \mathrm{M} \mathrm{ZnCl}_{2}$, and $25 \mu \mathrm{g} / \mathrm{mL}$ Bovine Serum Albumin (Sigma, St. Louis, MO). Assay products were analyzed by MALDI-TOF MS. Assays with the non-hydrolyzable ATP analogues were performed similarly, however, $5 \mathrm{mM}$ ATP was replaced by $5 \mathrm{mM}$ AMP-PNP or $5 \mathrm{mM}$ AMP-PCP. 
Assay of $\mathrm{His}_{6}$-LctA(1-43)W43A. MALDI-TOF MS calcd. 6678.3 Da (M), 6660.3 Da (M-H $\left.\mathrm{H}_{2} \mathrm{O}\right), 6642.3$ $\mathrm{Da}\left(\mathrm{M}-2 \mathrm{H}_{2} \mathrm{O}\right), 6624.3 \mathrm{Da}\left(\mathrm{M}-3 \mathrm{H}_{2} \mathrm{O}\right)$. Observed, $6674 \mathrm{Da}(\mathrm{M}), 6657.7 \mathrm{Da}\left(\mathrm{M}-\mathrm{H}_{2} \mathrm{O}\right), 6640.8 \mathrm{Da}(\mathrm{M}-$ $\left.2 \mathrm{H}_{2} \mathrm{O}\right), 6623.3\left(\mathrm{M}-3 \mathrm{H}_{2} \mathrm{O}\right), 6720.3\left(\mathrm{M}-2 \mathrm{H}_{2} \mathrm{O}+80\right), 6737.9\left(\mathrm{M}-\mathrm{H}_{2} \mathrm{O}+80\right)$.

Assay of His $_{6}$-LctA(1-43)S42pS/W43A. MALDI-TOF MS calcd. 6758.3 Da (M), 6740.3 Da (M- $\left.\mathrm{H}_{2} \mathrm{O}\right)$, $6722.3 \mathrm{Da}\left(\mathrm{M}-2 \mathrm{H}_{2} \mathrm{O}\right), 6624.3\left(\mathrm{M}-2 \mathrm{H}_{2} \mathrm{O}-\mathrm{H}_{3} \mathrm{PO}_{4}\right)$. Observed, 6756.1 Da (M), 6738.1 Da $\left(\mathrm{M}-\mathrm{H}_{2} \mathrm{O}\right), 6721$ $\mathrm{Da}\left(\mathrm{M}-2 \mathrm{H}_{2} \mathrm{O}\right), 6623.1 \mathrm{Da}\left(\mathrm{M}-2 \mathrm{H}_{2} \mathrm{O}-\mathrm{H}_{3} \mathrm{PO}_{4}\right)$.

Assay of $\mathrm{His}_{6}$-LctA(1-38)S28C/T33pT/C38A. MALDI-TOF MS calcd. 6224.7 Da (M), 6126.7 Da (M$\left.\mathrm{H}_{3} \mathrm{PO}_{4}\right)$, 6108.7 $\mathrm{Da}\left(\mathrm{M}-\mathrm{H}_{3} \mathrm{PO}_{4}-\mathrm{H}_{2} \mathrm{O}\right)$. Observed, $6109 \mathrm{Da}\left(\mathrm{M}-\mathrm{H}_{3} \mathrm{PO}_{4}-\mathrm{H}_{2} \mathrm{O}\right)$.

Assay of $\mathrm{His}_{6}-\mathrm{LctA}(1-44) \mathrm{S} 28 \mathrm{C} / \mathrm{T} 33 \mathrm{pT} / \mathrm{S} 35 \mathrm{pS} / \mathrm{S} 42 \mathrm{pS} / \mathrm{Q} 44 \mathrm{~A}$. MALDI-TOF MS calcd. $7120.5 \mathrm{Da}(\mathrm{M})$, $7022.5 \mathrm{Da}\left(\mathrm{M}-\mathrm{H}_{3} \mathrm{PO}_{4}\right), 6924.5\left(\mathrm{M}-2 \mathrm{H}_{3} \mathrm{PO}_{4}\right), 6826.5\left(\mathrm{M}-3 \mathrm{H}_{3} \mathrm{PO}_{4}\right)$. Observed, 7120.1 Da (M), 7020.7 Da $\left(\mathrm{M}-\mathrm{H}_{3} \mathrm{PO}_{4}\right), 6926.5 \mathrm{Da}\left(\mathrm{M}-2 \mathrm{H}_{3} \mathrm{PO}_{4}\right), 6828.4 \mathrm{Da}\left(\mathrm{M}-3 \mathrm{H}_{3} \mathrm{PO}_{4}\right)$.

\section{Assays with LetM and ADP}

An HPLC fraction containing the purified ligation product was resuspended in sterile millipore water and 2-5 $\mu \mathrm{L}$ were added to a buffer containing $50 \mathrm{mM}$ Tris- $\mathrm{HCl}, \mathrm{pH} 7.5,10 \mathrm{mM} \mathrm{MgCl} 2,560 \mu \mathrm{M}$ ADP, $10 \mathrm{mM}$ D-glucose, and $8.4 \mu \mathrm{M}$ hexokinase (Sigma, St. Louis, MO). The mixture was incubated at $25^{\circ} \mathrm{C}$ for at least 35 min prior to the addition of $\mathrm{His}_{6}-\mathrm{LctM}(1-3 \mu \mathrm{M})$. Assay products were analyzed by MALDI-TOF MS.

Assay of $\mathrm{His}_{6}$-LctA(1-38)S28C/T33pT/S35A/C38A. MALDI-TOF MS calcd. 6224.7 Da (M), 6126.7 $\mathrm{Da}\left(\mathrm{M}-\mathrm{H}_{3} \mathrm{PO}_{4}\right), 6108.7 \mathrm{Da}\left(\mathrm{M}-\mathrm{H}_{3} \mathrm{PO}_{4}-\mathrm{H}_{2} \mathrm{O}\right)$. Observed, $6127.4 \mathrm{Da}\left(\mathrm{M}-\mathrm{H}_{3} \mathrm{PO}_{4}\right)$.

Assay of $\mathrm{His}_{6}$-LctA(1-39). MALDI-TOF MS calcd. 6311.9 Da (M), 6213.9 Da (M-H $\left.\mathrm{H}_{3} \mathrm{PO}_{4}\right)$. Observed, 6213.2 $\mathrm{Da}\left(\mathrm{M}-\mathrm{H}_{3} \mathrm{PO}_{4}\right)$.

Assay of $\mathrm{His}_{6}-\mathrm{LctA}(1-44) \mathrm{S} 28 \mathrm{C} / \mathrm{T} 33 \mathrm{pT} / \mathrm{S} 35 \mathrm{pS} / \mathrm{S} 42 \mathrm{pS} / \mathrm{Q} 44 \mathrm{~A}$. MALDI-TOF MS calcd. $7120.5 \mathrm{Da}(\mathrm{M})$, $7022.5 \mathrm{Da}\left(\mathrm{M}-\mathrm{H}_{3} \mathrm{PO}_{4}\right), 6924.5\left(\mathrm{M}-2 \mathrm{H}_{3} \mathrm{PO}_{4}\right), 6826.5\left(\mathrm{M}-3 \mathrm{H}_{3} \mathrm{PO}_{4}\right)$. Observed, $7120.8 \mathrm{Da}(\mathrm{M})$, 7021.6 Da $\left(\mathrm{M}-\mathrm{H}_{3} \mathrm{PO}_{4}\right), 6923.5 \mathrm{Da}\left(\mathrm{M}-2 \mathrm{H}_{3} \mathrm{PO}_{4}\right), 6829 \mathrm{Da}\left(\mathrm{M}-3 \mathrm{H}_{3} \mathrm{PO}_{4}\right)$. The spectrum is shown in Figure $\mathrm{S} 1$. 


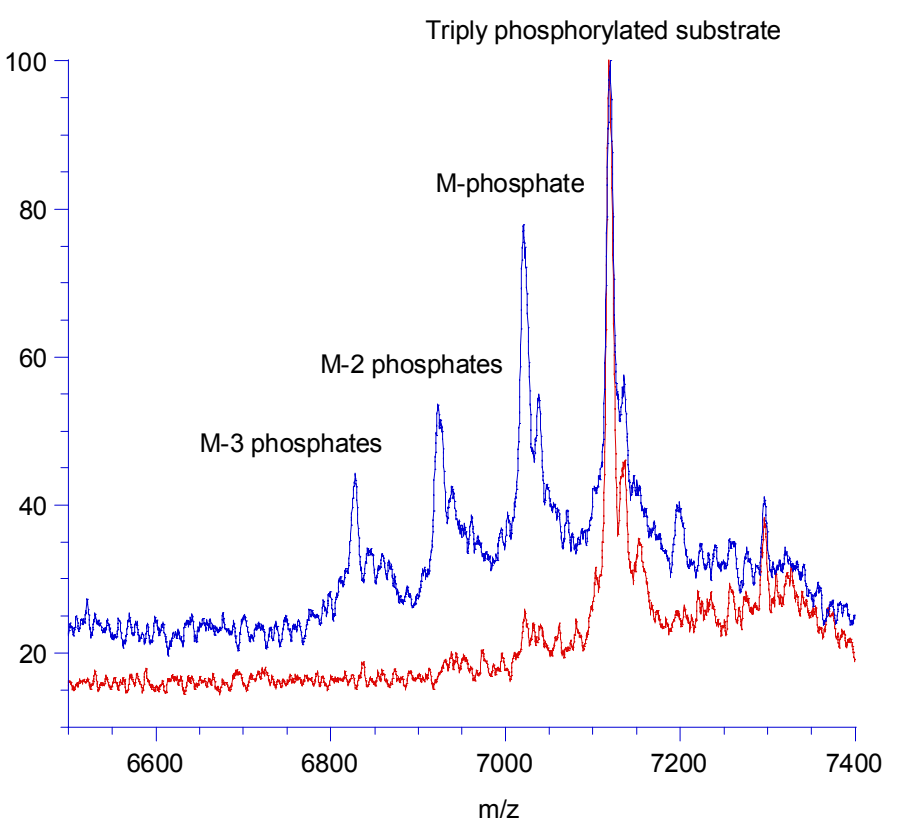

Figure S1. MALDI-TOF MS of LctM assay with the triply phosphorylated substrate His $_{6}$-LctA(144)S28C/T33pT/S35pS/S42pS/Q44A. The assay product in the presence of His ${ }_{6}$-LctM is shown in blue while a control assay is shown in red. All three phosphoamino acids undergo elimination in the presence of ADP and enzyme.

\section{Characterization of Assay Intermediates by ESI-FTMS}

All FTMS data was acquired on a custom-built 8.5 T Quadrupole-FTMS instrument which has been previously described. $^{5}$ HPLC fractions that had been dried were re-suspended in ESI spray solution (49\% $\mathrm{CH}_{3} \mathrm{CN}, 49 \% \mathrm{H}_{2} \mathrm{O}, 2 \%$ acetic acid). Samples that were purified on a C18 Zip-Tip were eluted into $4 \mu \mathrm{L}$ of $78 \% \mathrm{CH}_{3} \mathrm{CN}, 20 \% \mathrm{H}_{2} \mathrm{O}, 2 \%$ acetic acid and then diluted with $30 \mu \mathrm{L} 49 \% \mathrm{CH}_{3} \mathrm{CN}, 49 \% \mathrm{H}_{2} \mathrm{O}$, $2 \%$ acetic acid prior to introduction into the Q-FTMS via automated nanospray using a NanoMate 100 (Advion BioSciences). The single protein mode of ProSight PTM (https://prosightptm.scs.uiuc.edu was used to interpret MS/MS data. An italicized number following the relative molecular weight value $\left(\mathrm{M}_{\mathrm{r}}\right)$ indicates the number of heavy isotopes in the peak referenced. ${ }^{6}$

$M S / M S$ conditions - IRMPD. Ions of interest were isolated in the FTMS cell via a stored waveform inverse Fourier transform (SWIFT) typically about $2-5 \mathrm{~m} / \mathrm{z}$ wide, following which the ions were irradiated with a $75 \mathrm{~W} \mathrm{CO}_{2}$ laser for 150-300 ms.

$M S / M S$ conditions - SORI. Precursor ions were first enhanced by mass filtering in the quadrupole region (typically $40 \mathrm{~m} / \mathrm{z}$ region) and then the ion of interest was selectively isolated by SWIFT (typically $2-5 \mathrm{~m} / \mathrm{z}$ region). SORI was accomplished by activating the selected ions by the application of an off resonance frequency (typically $1000 \mathrm{~Hz}$ away) while pulsing in nitrogen gas to pressures of $\sim 10^{-6}$ torr. After the gas pulse, a $25 \mathrm{~s}$ pump down was applied before the excitation and detection of fragment ions. 
$M S / M S$ conditions $-E C D$. Ions fragmented by ECD were first enhanced in the quadrupole region (40 $\mathrm{m} / \mathrm{z}$ window) and then isolated via a SWIFT ( $\sim 2-5 \mathrm{~m} / \mathrm{z}$ region). Gas was pulsed into the cell to reach a pressure of $\sim 2 \times 10^{-9}$ torr after a relax time a dispenser cathode at a $1-2 \mathrm{~V}$ potential was used to introduce electrons into the cell for 100-200 ms.

\section{ESI-FT MS Characterization of His $\sigma_{-}$LctA(1-43)W43A assay products.}

In the broadband spectrum of the His $_{6}-\mathrm{LctA}(1-43) \mathrm{W} 43 \mathrm{~A}$ assay product (Fig S2 A), a species was observed at a mass consistent with 2 dehydrations $+80 \mathrm{Da}$ (6718.16-0 Da expt., 6718.12-0 Da theor.). The $7^{+}$charge state of that species was quadrupole enhanced and SWIFT isolated (Fig. S2 B) prior to fragmentation by IRMPD (Fig. S1 C). The fragment ion map (Fig. S2.D) shows $16 \mathrm{~b}$ ions and $1 \mathrm{y}$ ion. All of the $b$ ions up to and including $b_{43}$ match to the predicted sequence with no modifications. The $\mathrm{b}_{58}-\mathrm{b}_{60}$ ions all have masses consistent with two dehydrations, whereas the $\mathrm{b}_{61}$ ion correlates to a mass with three dehydrations. (Note that the numbering used for the fragment ions is different from LctA numbering. In the MS/MS numbering the His-tag and linker (line 1, Fig. S2.D) are included whereas LctA numbering starts with the leader peptide). It is known that a phosphoserine and phosphothreonine can eliminate under the conditions of MS/MS resulting in Dha or Dhb, which would have a mass equivalent to an enzymatic dehydration. ${ }^{7}$ A peak was observed -98 Da from the starting ion (Fig. S2 C), indicating that the phosphorylation was lost by $\beta$-elimination during MS/MS. Thus, two dehydrations were located to the region between the $b_{43}$ and $b_{58}$ ions, which contains Thr33 and Ser35 which have previously been shown to undergo dehydrations in the presence of LctM, and a third dehydration was localized to Ser42, consistent with phosphorylation taking place on one of the three residues that undergo dehydration by the action of LctM. 


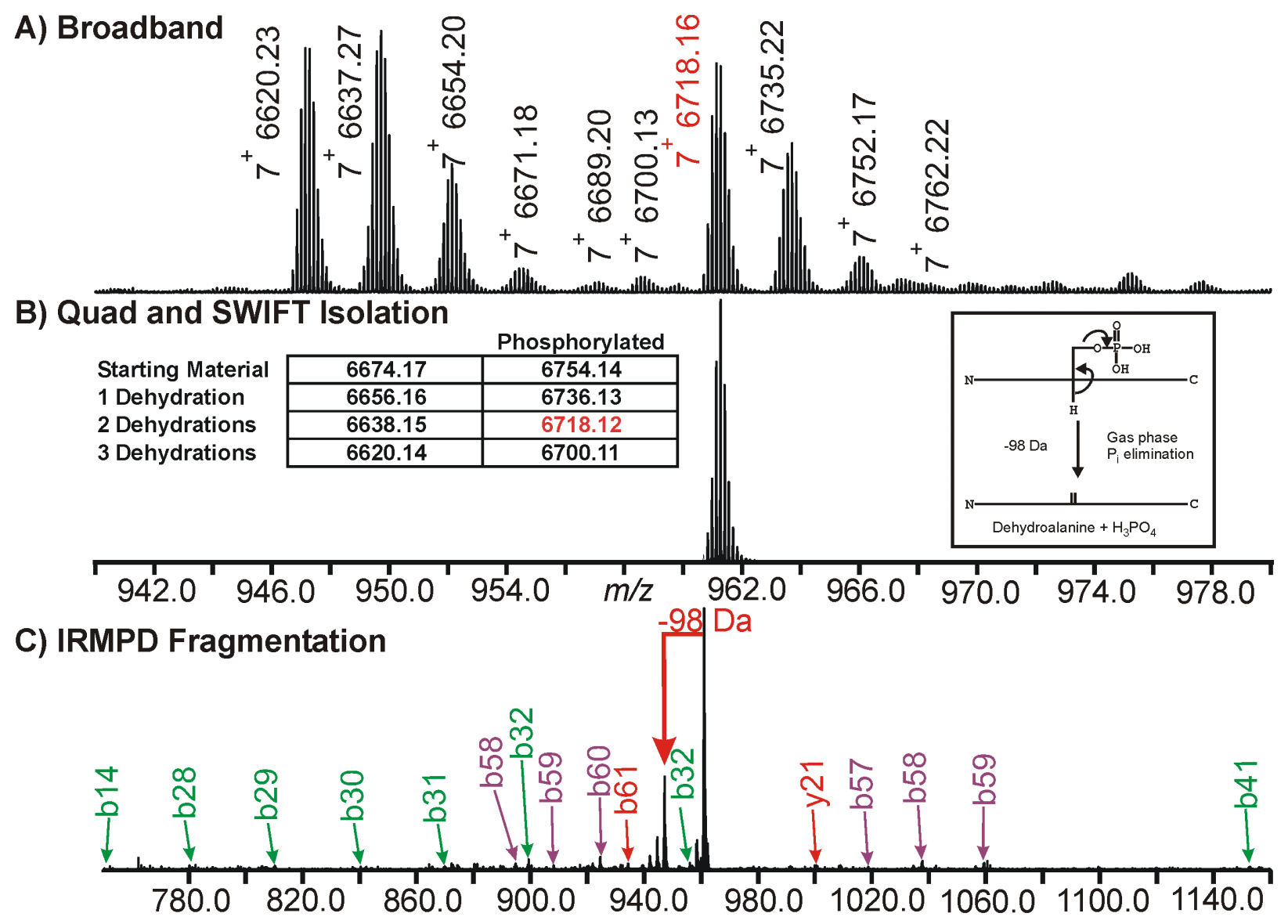

\section{D) Fragmentation Ion Map}

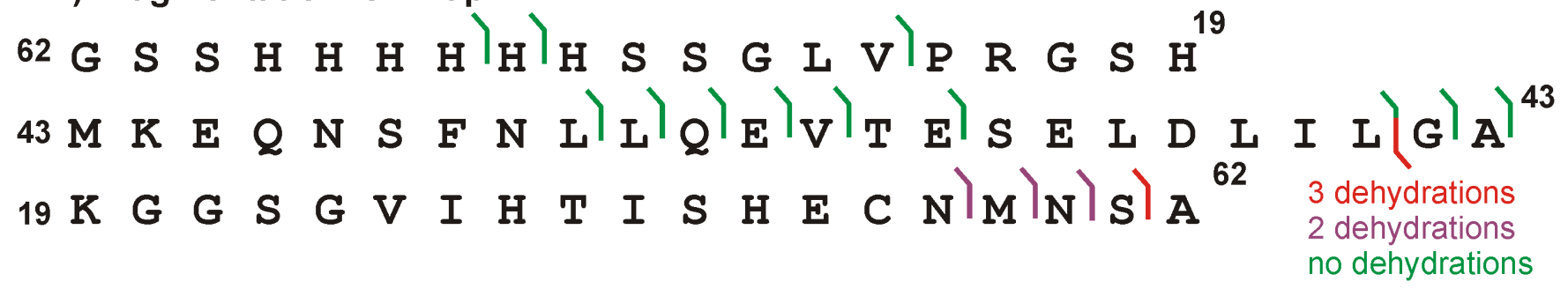

Figure S2. Isolation and fragmentation of a phosphorylated species. Note that the numbering used for the fragment ions is different from LctA numbering. In the MS/MS numbering the His-tag and linker (line 1, Fig S2.D) are included whereas LctA numbering starts with the leader peptide (line 2, Fig S2.D) A) Broadband spectrum showing all species present after an assay with His $_{6}$-LctA(1-43)W43A and LctM. The species highlighted in red corresponds to a doubly dehydrated species with one phosphorylation (see B inset table). B) The species highlighted in red in A) was quadrupole enhanced followed by SWIFT isolation. C) The $7^{+}$charge state of this ion was then fragmented via IRMPD and the resulting fragment ion map is shown in D). The green wedges indicate ions in which no dehydration occurred. The purple correspond to two dehydrations and the red fragment ion is a species which matches to the substrate with three dehydrations. No fragment ions were observed that were phosphorylated even though the only species isolated had a mass consistent with two dehydrations plus a phosphorylation (panel B). It is therefore likely that during IRMPD fragmentation this phosphorylated species underwent $\beta$-elimination to give a dehydrated species as indicated by the inset in B). Also the peak corresponding to -98 is indicative of $\beta$-elimination of a phosphorylated species. 
Fragmentation of the $\mathrm{M}-2 \mathrm{H}_{2} \mathrm{O}+80$ ion with electron capture dissociation (ECD) yielded $31 \mathrm{c}$ and 21 $z^{*}$ ions (Fig. S3) that are consistent with the phosphorylation being located in the propeptide. The $z_{12}$ fragment ion localizes two dehydrations and one phosphorylation to the C-terminal 12 residues. This region contains two Ser residues and one Thr that have previously been shown to undergo dehydration. ECD is a softer fragmentation technique than IRMPD or SORI and has the ability to retain labile posttranslational modifications such as phosphorylations, so all $z^{*}$ ions retain the +80 modification. ${ }^{8}$

Fragmentation Ion Map - ECD

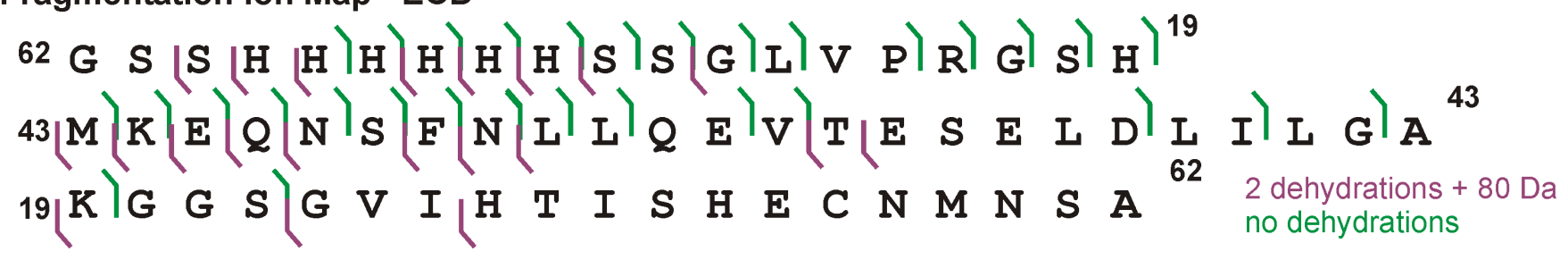

Figure S3. Fragment ion map for the $\mathrm{His}_{6}-\mathrm{LctA}(1-43) \mathrm{W} 43 \mathrm{~A}$ assay product with a mass consistent with $-2 \mathrm{H}_{2} \mathrm{O}+$ $80 \mathrm{Da}$ after fragmentation via ECD. Fragment ions indicated in purple contain the modifications $\left(-2 \mathrm{H}_{2} \mathrm{O}+80\right.$ $\mathrm{Da})$ whereas those indicated in green contain no modifications.

Also observed in the broadband spectrum of the $\mathrm{His}_{6}-\mathrm{LctA}(1-43) \mathrm{W} 43 \mathrm{~A}$ assay product is a species that has a mass consistent with one dehydration and one phosphorylation (6736.06-0 Da expt., 6736.12-0 Da theor.). After quadrupole enhancement of the region containing the peak of interest, the $8^{+}$charge state of the $-1 \mathrm{H}_{2} \mathrm{O}+80$ species was SWIFT isolated and fragmented by both IMRPD and SORI. IRMPD had $18 \mathrm{~b}$ ions and $4 \mathrm{y}$ ions consistent with the phosphorylation being in the propeptide (Fig. S4 A) and SORI had $17 \mathrm{~b}$ and $9 \mathrm{y}$ ions consistent with the phosphorylation being in the propeptide (Fig. S4 B). With IRMPD fragmentation, the $\mathrm{b}_{58}-\mathrm{b}_{61}$ fragment ions were all at a mass consistent with $-1 \mathrm{H}_{2} \mathrm{O}+80$ $\mathrm{Da}$ and the $\mathrm{y}_{28}$ was observed to contain the +80 . The $\mathrm{b}_{41}$ and $\mathrm{b}_{42}$ ions (Fig. S4.A) were observed with no modifications, therefore the $-1 \mathrm{H}_{2} \mathrm{O}$ and +80 was localized to the Ala24-Asn39 region (LctA numbering). Also observed were ions $-98 \mathrm{Da}$ lower than predicted, indicating that the phosphorylation had been eliminated resulting in a dehydrated residue. SORI fragmentation yielded the $b_{58}, b_{60}$ and $b_{61}$ ions which all contained the +80 species (Fig. S4.B). Also present were the $\mathrm{y}_{21}$ and $\mathrm{y}_{26}$ ions, which had masses consistent with $-1 \mathrm{H}_{2} \mathrm{O}+80 \mathrm{Da}$. These fragment ions localized the modifications $\left(-1 \mathrm{H}_{2} \mathrm{O}+80\right.$ Da) to Gly23-Asn39 (LctA numbering). 
A) Fragmentation Ion Map - IRMPD
62 G S S H H H H H H S S G L VlP R G S H

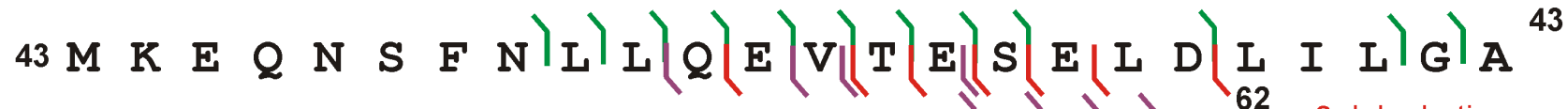

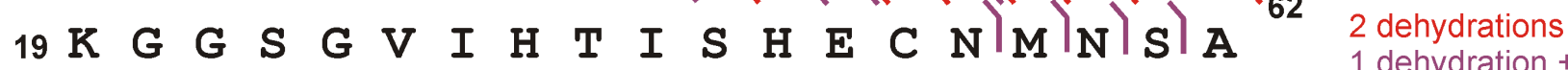
1 dehydration $+80 \mathrm{Da}$
no dehydrations

\section{B) Fragmentation Ion Map - SORI}

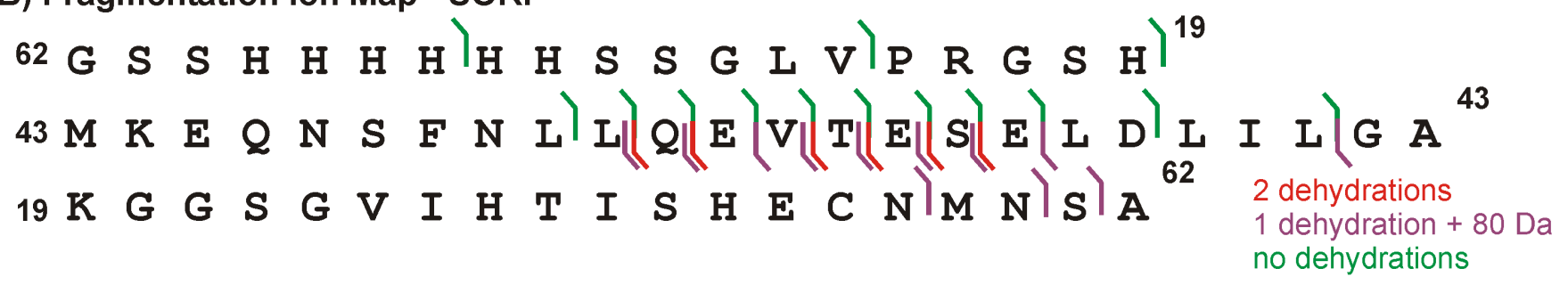

Figure S4. Fragment ion maps for the $-1 \mathrm{H}_{2} \mathrm{O}+80$ Da species observed as an assay product of the LctA(143)W43A mutant. A) IRMPD fragment ion map and B) SORI fragment ion map. The red wedges indicate species that have a mass consistent with 2 dehydrations, purple wedges correspond to those that have one dehydration $+80 \mathrm{Da}$ and green wedges indicate the ions that contain no modifications.

\section{Investigation of Cyclization by LctM}

The product from an assay of $119 \mu \mathrm{M}$ His $_{6}-\mathrm{LctA}(1-39) \mathrm{S} 28 \mathrm{C} / \mathrm{T} 33 \mathrm{pT} / \mathrm{S} 35 \mathrm{~A} / \mathrm{N} 39 \mathrm{~A}$ and $1.8 \mu \mathrm{M} \mathrm{His}_{6^{-}}$ LctM in the presence of $560 \mu \mathrm{M}$ ADP and $9 \mu \mathrm{M}$ hexokinase was purified by analytical C4 RPLC. The product (Figure S5, spectrum in blue) was then subjected to cyanylation with $100 \mathrm{mM}$ 1-cyano-4dimethylaminopyridinium tetrafluoroborate in the presence of $4 \mathrm{M} \mathrm{Gn}-\mathrm{HCl}, 1 \mathrm{mM}$ TCEP, and $100 \mathrm{mM}$ citric acid, $\mathrm{pH} 3.0$ (Figure S5, spectrum in red). The blue peak was displaced by $25 \mathrm{Da}$ indicating that a single thiol was present in the product that was cyanylated. In a control experiment, His 6 -LctA(139)S28C/T33pT/S35A/N39A was also subjected to cyanylation under identical conditions (Figure S6). The blue peak was displaced by $50 \mathrm{Da}$ indicating that two free thiols were present in the starting peptide. Hence, LctM cyclized the peptide in the absence of ATP. 


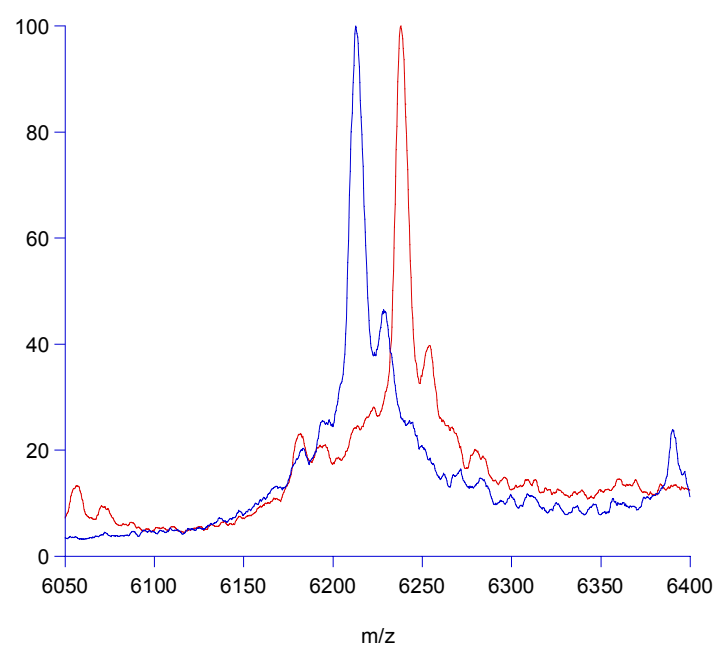

Figure S5. MALDI-TOF MS of the reaction of CDAP with the His ${ }_{6}-\mathrm{LctA}(1-39) \mathrm{S} 28 \mathrm{C} / \mathrm{T} 33 \mathrm{pT} / \mathrm{S} 35 \mathrm{~A} / \mathrm{N} 39 \mathrm{~A}$ assay product. In blue is shown the assay product prior to cyanylation (6213.2 Da). In red is the species observed after CDAP treatment exhibiting a single cyanylation (6238.5 Da).

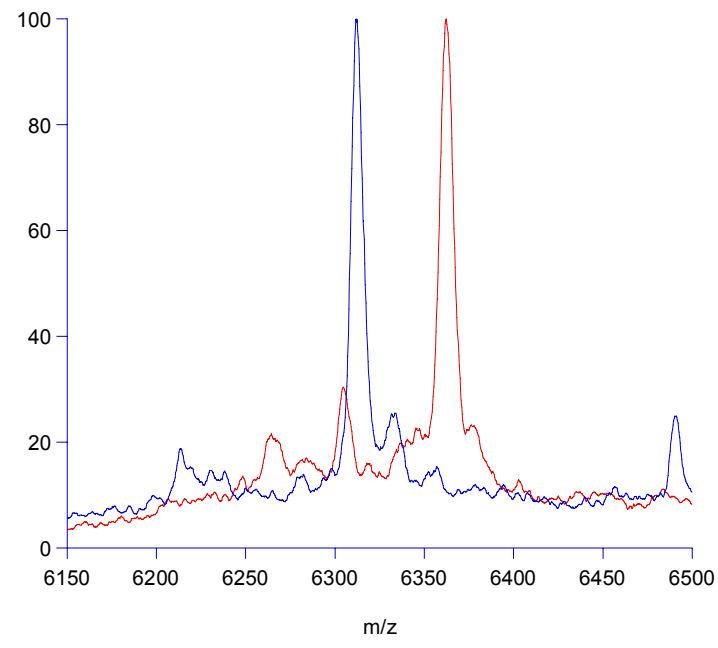

Figure S6. MALDI-TOF MS of the reaction of CDAP with His ${ }_{6}-\mathrm{LctA}(1-39) \mathrm{S} 28 \mathrm{C} / \mathrm{T} 33 \mathrm{pT} / \mathrm{S} 35 \mathrm{~A} / \mathrm{N} 39 \mathrm{~A}$. In blue is shown the peptide prior to cyanylation $(6312.5 \mathrm{Da})$. In red is the species observed after CDAP treatment demonstrating two cyanylations $(6362.5 \mathrm{Da})$.

\section{References}

1) Perich, J. W.; Ede, N. J.; Eagle, S.; Bray, A. M. Lett. Pept. Sci. 1999, 6, 91-97.

2) Sambrook, J.; Fritsch, E. F.; Maniatis, T. Molecular cloning: a laboratory manual; 2nd ed.; Cold Spring Harbor Laboratory: Cold Spring Harbor, New York, 1989.

3) Kaiser, E.; Colescott, R. L.; Bossinger, C. D.; Cook, P. I. Anal. Biochem. 1970, 34, 595-598. 
4) Han, Y.; Albericio, F.; Barany, G. J. Org. Chem. 1997, 62, 4307-4312.

5) Patrie, S. M.; Charlebois, J. P.; Whipple, D.; Kelleher, N. L.; Hendrickson, C. L.; Quinn, J. P.; Marshall, A. G.;

Mukhopadhyay, B. J. Am. Soc. Mass Spectrom. 2004, 15, 1099-1108.

6) Kelleher, N. L.; Lin, H. Y.; Valaskovic, G. A.; Aaserud, D. J.; Fridriksson, E. K.; McLafferty, F. W. J. Am. Chem. Soc. 1999, 121, 806-812.

7) Moyer, S. C.; Cotter, R. J.; Woods, A. S. J. Am. Soc. Mass Spectrom. 2002, 13, 274-283.

8) Stensballe, A.; Jensen, O. N.; Olsen, J. V.; Haselmann, K. F.; Zubarev, R. A. Rapid Commun. Mass Spectrom. 2000, 14, 1793-1800. 